\title{
Disseminated intravascular coagulation in acute promyelocytic leukaemia and its impact on the induction failure: a single centre study
}

\author{
Rahman $\mathrm{F}^{1}$, Kabir $\mathrm{AL}^{1}$, Khan $\mathrm{MR}^{1}$, Aziz A ${ }^{1}$, Baqui $\mathrm{MN}^{2}$, Dipta $\mathrm{TF}^{3}$, Yunus $\mathrm{ABM}^{1}$ \\ ${ }^{1}$ Dept. of Haematology, Bangabandhu Sheikh Mujib Medical University, Dhaka, ${ }^{2}$ Dept. of Pathology,Sir \\ Salimullah Medical College and Mitford Hospital Dhaka, ${ }^{3}$ Dept. of Transfusion Medicine, BIRDEM and \\ Ibrahim Medical College, Dhaka.Email: monikanuha@gmail.com
}

\begin{abstract}
Life-threatening coagulopathy associated with acute promyelocytic leukemia (APL) has been the defining clinical characteristic and is an important risk factor for fatal haemorrhage and early death. Pathogenesis of coagulopathy in APL is complex and mainly includes disseminated intravascular coagulation (DIC). The study was done to see the status of DIC and its impact on the outcome of APL in our setting. Among the total 60 patients, induction mortality rate was $30 \%$ and remission rate was $70 \%$. The main cause of induction mortality was bleeding that accounts for $66.7 \%$ of mortality. DIC was present among 32 out of 60 patients $(53.33 \%)$. Induction mortality has significant relationship to DIC as the induction mortality rate is $47 \%$ in patients with DIC and $11 \%$ in patient without DIC (P value 0.0009 ). Induction motality rate in low, intermediate and high risk group is $6.7 \%, 24 \%$ and $58 \%$ respectively ( $\mathrm{p}$ value $<0.0001$ ). Finally, risk group subclassification revealed presence of DIC in high risk group has the highest early mortality rate
\end{abstract}

\section{Introduction}

Induction mortality remains a major problem and is an important cause of treatment failure in management of acute promyelocytic leukemia (APL) and haemorrhage still accounts for the majority of such early deaths ${ }^{1}$. The introduction of All trans retinoic acid(ATRA) in initial therapy of acute promyelocytic leukemia represents one of the most spectacular advances in the treatment of human cancer ${ }^{2}$. Despite the development of highly effective treatment strategies for acute promyelocytic leukemia around $10 \%$ of patients die in the presentation period as a consequence of bleeding diathesis but the rate is as high as up to $30 \%$ in countries with limited resourses ${ }^{3.4}$. The coagulopathy of APL has been characterized as a form of disseminated intravascular coagulation (DIC) ${ }^{5}$. Recent reviews have focused mainly on the comparison of therapeutic approaches ${ }^{6-8}$. Understanding of the prognostic factors associated with the various forms of induction mortality in patients with APL has remained remarkably limited?. Supportive cares and other minor diagnostic and therapeutic aspects may have a crucial importance in patient outcome especially in the contest of low socioeconomic status where early mortality is high and overall survival is poor due to lack of proper facilities, adequate awareness and multidisciplinary approach regarding the management ${ }^{10-12}$. But no such studies have been done in our country so the Knowledge about the status of DIC management in patients of APL and its impact on the outcome in our setting may be helpful for further evaluation and treatment of the patients.

\section{Materials and Methods}

We reviewed data base of 60 APL patients in a terciary care hospital Bangabandhu Sheikh Mujib Medical University from July 2006 to December 2011 (5.5 years). Initial diagnosis was based on bone marrow morphological study with subsequent analysis of $\mathrm{t}(15,17)$ by cytogenetic analysis by FISH or PML RAR $\alpha$ rearrangement by RT PCR analysis. LAB diagnosis of DIC was based on changes in APTT, PT, FDP, D dimer and fibrinogen level. Patient was classified as according to the risk of relapse on the basis of $\mathrm{WBC}$, platelet count at diagnosis. Low risk WBC $<10,000 \times 10^{9} / \mathrm{L}$ and platelet $>40,000 \times 10^{9} / \mathrm{L}$; Intermediate risk WBC $<10,000 \times 10^{9} / \mathrm{L}$ and plt $<40,000 \times 10^{9} / \mathrm{L}$; high risk with $\mathrm{WBC}>10,000 \times 10^{9} / \mathrm{L}$ and platelet $<40,000 \times 10^{9} / \mathrm{L}^{\mathbf{1 3}}$. Induction was given with ATRA and idarubicin/daunorubicin. Treatment was started as soon as diagnosis of APL was made by morphologic criteria. 
A morphologic complete remission (CR) designation requires less than 5\% blast and atypical promyelocytes in an aspirate sample and an absolute neutrophil count of more than $1 \times 10^{9} / \mathrm{L}$ and platelet of more than $100 \times 10^{9} / \mathrm{L}^{9}$. Death due to different causes were defined as stated below.

Infection: When death is due to clinical, radiologic, or microbiologically documented infection.

Haemorrhage: When a major bleeding occurs in a vital organ (central nervous system, lungs). Gastrointestinal tract haemorrhage requires massive melena or haemostasis accompanied by fall in blood pressure.

Differentiation syndrome (DS): That is, death occurring in patients with definitely present DS and not explained by infection, haemorrhage or any other cause ${ }^{14}$. Definitely present DS is defined as the presence of at least 4 of the characteristic signs and symptoms described by Frankel et al: fever, dyspnea, pleural effusion, pulmonary infiltrates, renal failure, hypotension, and unexplained weight gain greater than $5 \mathrm{~kg}^{15}$.

Statistical analysis was done by chi squire $\left(\chi^{2}\right)$ test and two sample $\mathrm{Z}$ test of proportion.

\section{Results}

Some pretreatment charecteristics and demographic data are placed in table I. Median age was 32.42 year. Male female ratio is $1.72: 1$. Median WBC count is $10.5 \times 10^{9} / \mathrm{L}$, (range $0.5-350$ ). Median platelet count $30 \times 10^{9} / \mathrm{L}$ range (6-180). DIC was present in 32 out of 60 patients (53.33\%). Among total 60 patients 42 were abled to achieved remission $(70 \%)$ after induction and mortality occurs to $18(30 \%)$, so induction mortaliy was the main cause of induction failure. Induction mortality occurs to 18 patients of which $66.7 \%$ (12) was due to bleeding, $22.2 \%$ (4) was due to sepsis and $11.1 \%$ (2) was due to differentiation syndrome. Frequency of low risk patients is $15(25 \%)$, intermediate risk patients is $25(41.7 \%)$, high risk patient is $20(33.33 \%)$. Among low, intermediate and high risk APL patients DIC was present in $5(33.33 \%), 14(56 \%)$ and $13(65 \%)$ patients respectively.

Table II reveals Early mortality rate is $47 \%$ in patients who have DIC and is $11 \%$ in patients without DIC ( $\mathrm{p}$ value <0.0001). Among low, intermediate and high risk patients induction mortality occurs to $1(6.6 \%), 6(28 \%)$ and $11(32.5 \%)$ patients respectively ( $\mathrm{P}$ value $<0.0001)$.

So DIC and induction mortality were more frequent in high risk group and high rate of induction mortality is statistically significant in high risk group. Risk group subclassification is done on the basis of initial platelet count and WBC count. High risk group has WBC count more than $10,000 / \mathrm{cmm}$ and platelet count less than $40,000 / \mathrm{cmm}$. Table III shows both the two parameters of high risk group individually has significant relationship with induction mortality ( $\mathrm{p}$ value is $<0.0001$ and 0.02 respectively).

Table I: Selected clinical, laboratory and outcome data of 60 APL patients

\begin{tabular}{ll}
\hline Patients charecteristics & value/frequency (percentage) \\
\hline Age median(range) & $32.42(14-70)$ \\
Sex & $38(68.3 \%)$ \\
$\quad$ Male & $22(36.7 \%)$ \\
$\quad$ Female & $10.5(0.5-350)$ \\
WBC count- median(range) $\times 10^{9} / \mathrm{L}$ & $30(6-180)$ \\
Platelet counts- median (range) $\times 10^{9} / \mathrm{L}$ & \\
Risk group & 15 \\
$\quad$ Low risk & 25 \\
$\quad$ Intermediate & 20 \\
$\quad$ High risk & $32(53.33 \%$ \\
Laboratory evidence of DIC at diagnosis & $5(33.33 \%)$ \\
$\quad$ Low risk & $14(56 \%)$ \\
$\quad$ Intermediate risk & $13(65 \%)$ \\
High risk & \\
Outcome after inductiuon therapy (n-60) & $18(30 \%)$ \\
$\quad$ Induction mortality & $30(70 \%)$ \\
$\quad$ Remission & \\
Causes after induction mortality (n- 18) & $12(66.33 \%)$ \\
Bleeding & $4(22.11 \%)$ \\
Infection & $2(11.05 \%)$ \\
Differentiation syndrome & \\
\end{tabular}

Table II: Causes of induction mortality and its relation to presence of DIC and risk group

\begin{tabular}{lcc}
\hline Events & $\begin{array}{c}\text { No. of induction } \\
\text { mortality (Percentage) }\end{array}$ & p value \\
\hline Patients with DIC (n=32) & $15(47 \%)$ & $<0.0001^{*}$ \\
Patients without DIC & $3(11 \%)$ & \\
Risk group & & \\
Low & $1(6.7 \%)$ & \\
Intermediate & $6(24 \%)$ & \\
High & $11(58 \%)$ & \\
\hline
\end{tabular}

*P value is detected by 2 sample $\mathrm{Z}$ test of proportion of $95 \%$ confidence interval

Table III: Relationship between 2 variables of high risk group and induction mortality

\begin{tabular}{llll}
\hline Variables & \multicolumn{2}{l}{ Induction mortality $(\mathrm{n}=18)$} & \\
& Present $(\%)$ & Aabsent $(\%)$ & p value \\
\hline $\begin{array}{l}\text { WBC count } \\
10 \times 10^{9} / \mathrm{L} \text { or more }\end{array}$ & $16(89 \%)$ & $14(33 \%)$ & $<.0001$ \\
$\begin{array}{l}\text { Platelet count less } \\
\text { than } 40 \times 10^{9} / \mathrm{L}\end{array}$ & $14(78 \%)$ & $19(45 \%)$ & 0.02 \\
\hline
\end{tabular}

\section{Discussions}

Early haemorrhagic deaths were the main cause of induction failure in acute promyelocytic leukaemia (APL) before the introduction of ATRA ${ }^{16}$. But in ATRA era several studies reporting results with 
ATRA base chemotherapy have shown that early death rates reported are up to $10 \%$ and cause remains haemorrhage in up to $30-60 \%$ of patients ${ }^{\mathbf{7 , 9}}$. Article by Park et al strongly suggests that the rate of early death in APL is unexpectedly much higher than commonly believed, indicating that this number must be revised, taking into account real-world data ${ }^{17}$. According to Stein E et al, patients with APL may die early of haemorrhage at the time of presentation before registration in to clinical trials ${ }^{3}$. Studies in several Latin American countries revealed the problem is more intense in developing countries where the needed aggressive supportive care is unavailable $\mathrm{e}^{\mathbf{1 3}}$. Our study revealed induction mortality rate is $30 \%$ and cause remained haemorrhage in $66.7 \%$ of cases. Studies done among 134 APL Brazilian patients revealed similar type induction mortalitry rate and cause of death ${ }^{\mathbf{1 8}}$. Inspite of the difference in rate of induction mortality causes are similar to both in developed and developing countries, ${ }^{\mathbf{7 , 9 1 8}}$. According to Breccia $M$ et al and De la Serna $J$ et al. induction mortality is significantly higher in patients with $\mathrm{DIC}^{\mathbf{4 , 9}}$. Univariate anlysis revealed presence of DIC is one of the bad prognostic factor for induction mortality and multivariate analysis revealed DIC is a risk factor for the haemorrhagic cause of early mortality 9 . Our study has shown that presence of DIC and induction mortality has highly significant relationship. Risk group subclassification is done to categorize patients for giving risk adopted treatment protocol mainly in consolidation $^{\mathbf{7}, \mathbf{8}}$. Again the study revealed that high risk group is has high induction mortality rate than low risk group that is similar to study done among 134 brazilian patients ${ }^{18}$. WBC count more than 10x $10^{9} / \mathrm{L}$ and platelet count less than $40 \times 10^{9} / \mathrm{L}$ individually has positive relationship with induction mortality. In the context of our setting management of DIC in higher risk group is more challenging than that of in low risk group as because presence of high WBC count and low platelet count in association with DIC is more difficult to manage in countries with limited resourses where prompt diagnosis, supportive management and patient monitoring is inadequate $^{\mathbf{1 2}}$. So it may lead to the conclusion that presence of DIC among high risk group is responsible for the main burden of induction failure where aggressive supportive care is needed and management of this remains the main challenge for us. So during management of DIC risk group subclassification of patient is important to identify and categorize patient who need more attention to prevent induction mortality.

Conclusion: With a view to reduce the gap in outcome between the developed and those in developing countries quicker diagnosis and better supportive cares, early recognition and treatment of life threatening complications are required. Our study reveals that the high risk group having DIC has the highest induction mortality rate. So risk group subclassification is an important issue not only for evaluation of risk of relapse but also for to prevent early mortality related to coagulopathy and DIC by giving better attention, intensive supportive care and expart management plan.

\section{Acknowledgements}

This work was supported by department of Haematology, Bangabandhu Sheikh Mujib Medical University, Dhaka, Bangladesh.

\section{References}

1. Choudhury A, DeLoughery T G. Bleeding and thrombosis in acute promyelocytic leukemia. American Journal Hematol 2012; 87: 596-603.

2. Lo-Coco F, Ammatuna E. The Biology of Acute Promyelocytic Leukemia and Its Impact on Diagnosis and Treatment. Haematology Am Soc Hematol Educ Program 2006; 1: 156-161.

3. Stein E, McMahon B, Kwaan H, Altman J K, Frankfurt $\mathrm{O}$, Tallman M S. The coagulopathy of acute promyelocytic leukaemia revisited. Best Practice \& Research Clinical Haematology 2009; 22: 153-163.

4. Breccia M, Latagliata R, Cannella L, Minotti C, Meloni G, Lo-Coco F. Early hemorrhagic death before starting therapy in acute promyelocytic leukemia: association with high white blood cell count, late diagnosis and delayed treatment initiation. Haematologica 2010; 95: 853-854.

5. Arbuthnot C, Wilde JT. Haemostatic problem in acute promyelocytic leukemia. Blood 2006;20: 289-97.

6. Sanz M A, Montesinos P, Rayo'n C et al. Riskadapted treatment of acute promyelocytic leukemia based on all-trans retinoic acid and anthracycline with addition of cytarabine in consolidation therapy for high-risk patients: further improvements in treatment outcome, Prepublished online April 14, 2010; 115: 5137-5146.

7. Lo-Coco F, Avvisati G, Vignetti $\mathrm{M}$ et al. Front-line treatment of acute promyelocytic leukemia with AIDA induction followed by risk-adapted consolidation for adults younger than 61 years: results of the AIDA-2000 trial of the GIMEMA Group. Blood 2010; 116: 31713179.

8. Tomoki Naoe, Eva Lengfelder, Thomas Büchner et al. Management of acute promyelocytic leukemia: recommendations from an expert panel on behalf of the European Leukemia Net. Blood 2009; 113: 1875-1891.

9. De la Serna J, Montesinos P, Vellenga E et al. Causes and prognostic factors of remission induction failure in 
patients with acute promyelocytic leukemia treated with all-trans retinoic acid and idarubicin. Blood 2008;111:3395-3402.

10. Sanz MA, Tallman MS, Lo-Coco F. Practice point, consensus and controversial issues in the management of patients with newly diagnosed acute promyelocytic leukemia. Oncologist. 2005;10:806-14.

11. Sanz MA, Tallman MS, Lo-Coco F. Tricks of the trade for the appropriate management of acute promyelocytic leukemia. Blood 2005;105:3019-3025.

12. Reberio RC, Rego E. Management of APL in developing countries: epidemiology, challenges and opportunities for internatonal collaboration. Haematology Am Soc Hematol Educ Program. 2006;1: 162-8.

13. Sanz M A, Coco F L, Martin G et al. Definition of relapse risk and role of nonanthracycline consolidation in patients with acute promyelocytic leukemia; a joint study of the PATHEMA and GIMEMA cooperative groups: Presented in part at the $41^{\text {st }}$ meeting of the American Society of Haematology, New Orleans, LA, December 3-7, 1999.
14. Frankel SR, Eardley A, Heller G et all. Alltransretinoic acid for acute promyelocytic leukemia. Results of the New York study. Ann Intern Med 1994;120:278-286.

15. Sanz M A, Martın G, Gonzalez M et al. Riskadapted treatment of acute promyelocytic leukemia with all-trans-retinoic acid and anthracycline monochemotherapy: a multicenter study by the PETHEMAgrou. Blood 2004; 103: 1237-1243.

16. Park J H, Qiao B, Panageas K S et al.Early death rate in acute promyelocytic leukemia remains high despite all-trans retinoic acid: Blood 2011; 118: 1248-1254.

17. Bona E D, Avvisati G, Castaman G et al. Early haemorrhagic morbidity and mortality during remission induction with or without all-trans retinoic acid in acute promyelocytic leukaemiaI . British Journal of Haematology 2000; 108:689-695.

18. Jacomo R H, Melo R A M, Souto F R et al.Clinical features and outcomes of 134 Brazilians with acute promyelocytic leukemia who received ATRA and anthracyclines. Haematologica 2007; 92: 1431-1432. 